\title{
Unit of Specific Entropy
}

National Cancer Institute

\section{Source}

National Cancer Institute. Unit of Specific Entropy. NCI Thesaurus. Code C70450.

A unit used to express the entropy of the unit mass of the system. 